\title{
Comment on "Origin of water in the Badain Jaran Desert, China: new insight from isotopes" by Wu et al. (2017)
}

\author{
Lucheng Zhan ${ }^{1}$, Jiansheng Chen ${ }^{2}$, Ling Li ${ }^{3}$, and David A. Barry ${ }^{4}$ \\ ${ }^{1}$ State Key Laboratory of Hydrology-Water Resources and Hydraulic Engineering, Hohai University, Nanjing, 210098, China \\ ${ }^{2}$ College of Earth Sciences and Engineering, Hohai University, Nanjing, 210098, China \\ ${ }^{3}$ School of Civil Engineering, the University of Queensland, St. Lucia, QLD 4072, Australia \\ ${ }^{4}$ Laboratoire de technologie écologique (ECOL), Institut d'ingénierie de l'environnement (IIE), \\ Faculté de l'environnement naturel, architectural et construit (ENAC), Ecole Polytechnique \\ Fédérale de Lausanne (EPFL), Station 2, 1015 Lausanne, Switzerland
}

Correspondence: Jiansheng Chen (jschen@hhu.edu.cn)

Received: 27 April 2018 - Discussion started: 8 May 2018

Revised: 26 July 2018 - Accepted: 3 August 2018 - Published: 22 August 2018

\begin{abstract}
Precipitation isotope data were used to determine the origin of groundwater in the Badain Jaran Desert (BJD) in the study of $\mathrm{Wu}$ et al. (2017). Both precipitation and its isotope composition vary seasonally, so arithmetic averages of precipitation isotope values poorly represent the isotope composition of meteoric water. Their finding that the BJD groundwater is recharged by modern meteoric water from local areas including the southeastern adjacent mountains was based on arithmetic averaging. However, this conclusion is not supported by the corrected mean precipitation isotope values, which are weighted by the precipitation rate. Indeed, the available isotopic evidence shows that modern precipitation on the Qilian Mountains is more likely to be the main source of the groundwater and lake water in the BJD, as found by Chen et al. (2004).
\end{abstract}

\section{Introduction}

The Badain Jaran Desert (BJD) is characterized by a unique landscape that contains a large number of lakes and the world's largest stationary sand dunes maintained by groundwater (Chen et al., 2004). However, the origin of the groundwater remains uncertain (Dong et al., 2013). Using stable and radioactive environmental isotopes, Wu et al. (2017) investigated the connection between lakes and groundwater, and the origin of groundwater in the southeastern desert area. They suggested that the BJD groundwater is derived primar- ily from modern meteoric water from local areas, including the southeastern adjacent small mountains. Based on isotopic evidence, the authors ruled out other hypotheses on the groundwater source, including fossil groundwater (Gates et al., 2008; Ma and Edmunds, 2006; Wang et al., 2015; Yang et al., 2010) and snowmelt from the Qilian Mountains, $500 \mathrm{~km}$ (center-to-center distance) southwest of the desert (Chen et al., 2004, 2006).

The authors argued that the ${ }^{14} \mathrm{C}$ dating overestimated the age $(\sim 10 \mathrm{ka})$ of the BJD groundwater due to interference by additional dead carbon input from ancient carbonates. We have conducted work related to the ${ }^{14} \mathrm{C}$ dating and found the same problem with overestimation of the groundwater age (Chen et al., 2014; Wang and Chen, 2018). Wu et al. (2017) reasoned that the average age of groundwater in the BJD should be much younger, since it includes modern meteoric water as indicated by tritium levels (Gates et al., 2008; Wu et al., 2017). They presented much evidence and discussion for their conclusion of groundwater recharged by modern precipitation from local areas. However, their averaging of the precipitation isotope data did not account for seasonality of precipitation amount, which led to a misconception of the potential groundwater origin. 


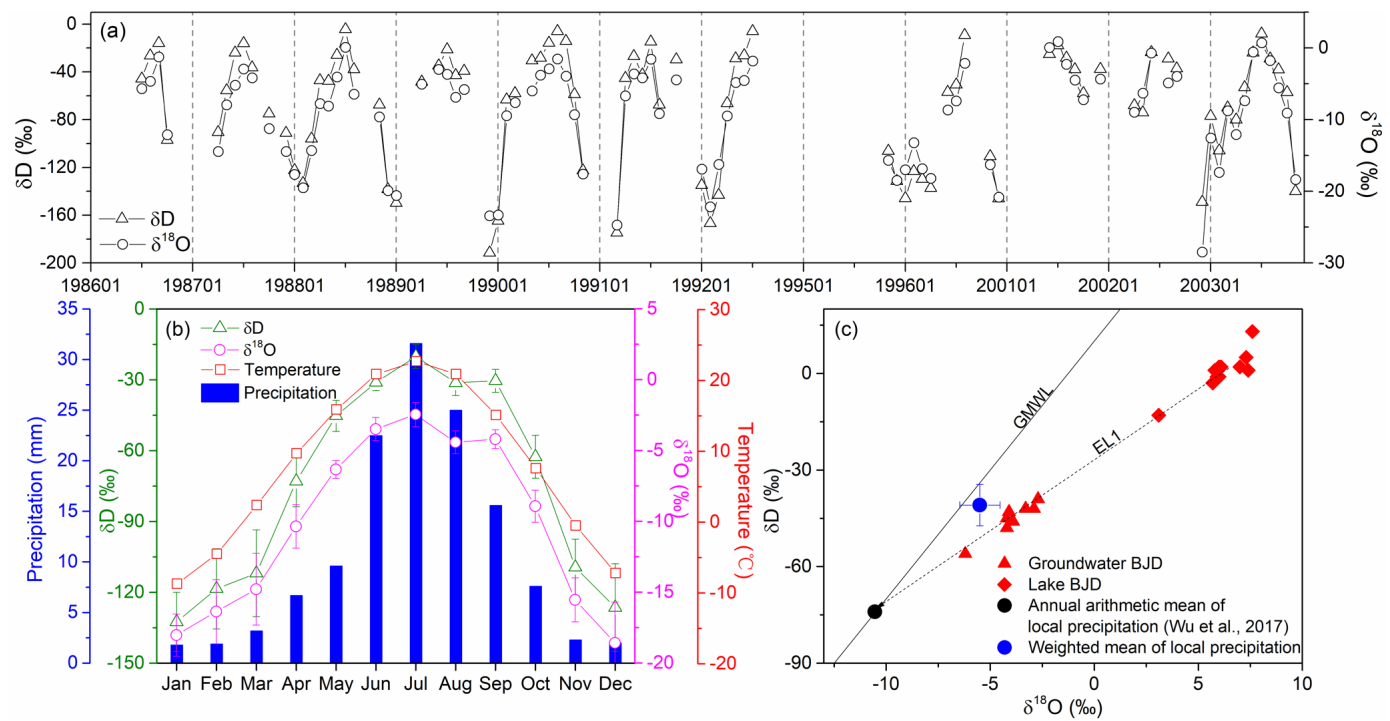

Figure 1. Isotope composition of monthly precipitation of GNIP station Zhangye (all available datasets a, and monthly mean values b), and $\delta \mathrm{D}-\delta^{18} \mathrm{O}$ plots of groundwater, lake water and annual precipitation in the study area (based on data from Zhangye station) (c). Data in (a) and (b) are sourced from the GNIP database, while plot (c) is modified from Wu et al. (2017). Statistical mean values are shown together with standard errors where feasible.

\section{Source water identification based on weighted mean precipitation isotope values}

The determination of mean precipitation isotope values is of great significance for assessing the contribution of precipitation as a water source to regional hydrological systems and for assessing interactions among different hydrological components. To examine the relationship between the BJD groundwater and local precipitation, historical precipitation isotope data from a nearby GNIP (Global Network of Isotopes in Precipitation, https://nucleus.iaea.org/wiser/ index.aspx, last access: 24 July 2018) station in Zhangye (1986-2003) were used by Wu et al. (2017). The GNIP database provides data on monthly precipitation isotopes as well as monthly rainfall for the Zhangye station. As shown in Fig. $1 \mathrm{a}, \mathrm{b}$, the monthly $\delta \mathrm{D}$ and $\delta^{18} \mathrm{O}$ values in the study area exhibit large seasonal variations, which are mainly controlled by temperature (Zhan et al., 2017). The isotopic seasonality pattern of precipitation is similar in different years. During the summer half year when temperature is higher, the rainfall is more enriched in heavier isotopes.

According to the GNIP data, the mean annual precipitation is about $130 \mathrm{~mm}$, with more than $60 \%$ of the total annual rainfall occurring from June to August, during which the isotope values are the highest (Fig. 1b). Since the annual precipitation is seasonal, the monthly precipitation isotope data should be weighted by the monthly precipitation amount to calculate the annual mean for representing the isotope composition of local precipitation as a potential source of the BJD groundwater. The weighted mean isotopic values $\overline{\delta_{w}}$ can be calculated using

$$
\overline{\delta_{w}}=\frac{\sum_{j=\mathrm{Jan}}^{\text {Dec }} \overline{\delta_{j}} \cdot \overline{P_{j}}}{\sum_{j=\mathrm{Jan}}^{\text {Dec }} \overline{P_{j}}},
$$

where $\overline{\delta_{j}}$ and $\overline{P_{j}}$ are the averaged isotopic values and averaged rainfall amount of month $j$ during the GNIP observation years, respectively. The monthly averages, $\overline{\delta_{j}}$ and $\overline{P_{j}}$ can be calculated as follows:

$\begin{aligned} \overline{\delta_{j}} & =\frac{\sum_{i} \delta_{i, j}}{n}, \\ \overline{P_{j}} & =\frac{\sum_{i} P_{i, j}}{n},\end{aligned}$

where $\delta_{i, j}$ and $P_{i, j}$ are the isotopic value $\left(\delta \mathrm{D}\right.$ or $\left.\delta^{18} \mathrm{O}\right)$ and rainfall amount of month $j$ in year $i$ from the available GNIP dataset, respectively, and $n$ is the corresponding number of available data.

Based on the dataset from the GNIP database, the calculated weighted mean values for $\delta \mathrm{D}$ and $\delta^{18} \mathrm{O}$ of Zhangye's precipitation are $-40.9 \%$ and $-5.50 \%$, respectively (Fig. 1c). Using arithmetic averages, Wu et al. (2017) determined $\delta \mathrm{D}$ and $\delta^{18} \mathrm{O}$ values around $-74 \%$ o and $-10.5 \%$, respectively. When plotted on the $\delta^{18} \mathrm{O}-\delta \mathrm{D}$ graph (Fig. 1c), the arithmetic average values are close to the intersection of evaporation line EL1 (for groundwater and lake water in the desert) and the GMWL (Global Meteoric 

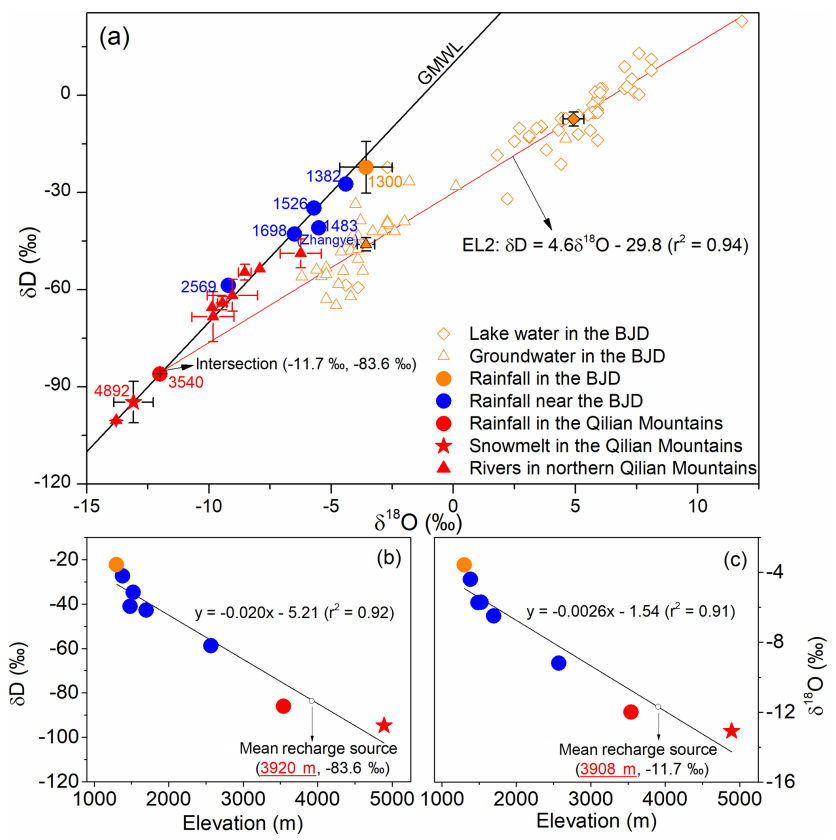

Figure 2. $\delta \mathrm{D}$ vs. $\delta^{18} \mathrm{O}$ plot of water related to the BJD groundwater origin (a), and altitude gradients of related precipitation isotopes $(\mathbf{b}, \mathbf{c})$. For precipitation (rainfall and snowmelt), the corresponding sampling elevations (ma.s.l.) are also shown. Statistical mean values are shown together with standard errors where feasible. The weighted means of local rainfall (blue circles) are from $\mathrm{Wu}$ et al. (2010) and the GNIP database. Rainfall (yellow circle), lake water (yellow rhombus; 47 samples) and groundwater (yellow triangle; 31 samples) within the BJD area are based on data from $\mathrm{Wu}$ et al. (2017), Ma and Edmunds (2006), Zhao et al. (2012), Gates et al. (2008), Chen et al. (2012) and Yang et al. (2010). Summer rainfall (red circle; 4 samples) and snowmelt (red pentagram; 15 samples) in the Qilian Mountains are based on data from Ren (1999). Isotopic data for various rivers (red triangles) on the northern slope of the Qilian Mountain are collected from Chen et al. (2012), Li et al. (2016), Zhu et al. (2008) and Ren (1999).

Water Line), which led $\mathrm{Wu}$ et al. (2017) to conclude that groundwater and lake water in the BJD originate from modern meteoric precipitation in local areas including the adjacent small mountains. However, if the weighted mean values are used, this conclusion no longer holds. Compared with the isotope composition of the local precipitation, the source water recharging the BJD groundwater and lakes is much more depleted in $\mathrm{D}$ and ${ }^{18} \mathrm{O}$.

\section{Reanalysis on the origin of groundwater in the BJD}

Using available data from the literature, we reanalyzed the possible origin of groundwater in the BJD. We focus on the BJD southern margin area where the desert lakes are mostly concentrated. The isotope data of the groundwater and lake water (Fig. 2a) lie on evaporation line EL2 $\left(\delta \mathrm{D}=4.6 \delta^{18} \mathrm{O}-29.8, r^{2}=0.94\right)$, which is reasonably simi- lar to EL1 in Wu et al. (2017). Here only data from groundwater and lake water samples within the BJD area were used for determining the EL2. The weighted mean isotope values of precipitation in the regions close to the BJD (blue circles) show a decreasing trend with increasing elevation from 1382 to $2569 \mathrm{~m}$ a.s.l., reflecting the effect of elevation on isotope fractionation (Poage and Chamberlain, $2001)$. The intersection of EL 2 and GMWL $(\delta \mathrm{D}=-83.6 \%$, $\delta^{18} \mathrm{O}=-11.7 \%$ ), which represents the mean isotope composition of the recharge source for BJD groundwater, is outside the range of precipitation in the local and adjacent regions, indicating another different source water with more depleted isotope composition.

Together with the statistical isotopic values of precipitation in the BJD and the Qilian Mountains (rainfall and snowmelt) from literature data, a significant inverse correlation of $\delta \mathrm{D}$ and $\delta^{18} \mathrm{O}$ values with elevation of the precipitation can be established (Fig. 2b, c). The altitude gradients for $\delta \mathrm{D}$ and $\delta^{18} \mathrm{O}$ are $-2.0 \% \circ 100 \mathrm{~m}^{-1}$ and $-0.26 \% \circ 100 \mathrm{~m}^{-1}$, respectively, which are close to global mean levels (Poage and Chamberlain, 2001). Based on these gradients, the location of water associated with the intersection of EL2 and GMWL corresponds to an average elevation of $3914 \mathrm{~m}$ a.s.l. ( $3920 \mathrm{~m}$ estimated by $\delta \mathrm{D}$ and $3908 \mathrm{~m}$ by $\delta^{18} \mathrm{O}$ ). Therefore, the recharge region for groundwater and lake water in the BJD is likely to include areas of elevations higher than $3914 \mathrm{~m}$ a.s.l. to produce source water of more depleted isotope composition.

The closest region that could meet this elevation requirement is the Qilian Mountains (average elevation between 4000 and $5000 \mathrm{~m}$ a.s.l.), northeast of the QinghaiTibet Plateau (Fig. 3a). Nineteen snowmelt and rainfall water samples from 3540 to $5010 \mathrm{~m}$ a.s.l. in the glacier zone of the Qilian Mountains were collected by Ren (1999). The statistical isotope compositions of these samples are close to that given by the GMWL-EL2 intersection (Fig. 2a). Therefore, the isotope evidence points to the Qilian Mountains as a main source region for groundwater and lake water in the BJD, as observed previously (Chen et al., 2004).

Wu et al. (2017) ruled out the Qilian Mountains as a recharge area for groundwater in the BJD based on the large isotopic difference between the GMWL-EL2 intersection and data from water samples mainly collected from the Shiyang River watershed (Li et al., 2016), which is located in the eastern lower area of the Qilian Mountains. The mean elevation of the Shiyang River watershed is only $2487 \mathrm{~m}$ a.s.l. (Bourque and Hassan, 2009), which is lower than the mean elevation of the entire mountain. Therefore, their argument for excluding the Qilian Mountains as a recharge region is questionable. Water samples collected from rivers on the northern slope of the Qilian Mountains are characterized by large variations of isotope compositions (Fig. 2a), with the lowest isotopic values found by Ren (1999) from a river in the upstream glacier zone. Scattered data between the plots of snowmelt on the mountain and rainfall in lower regions 


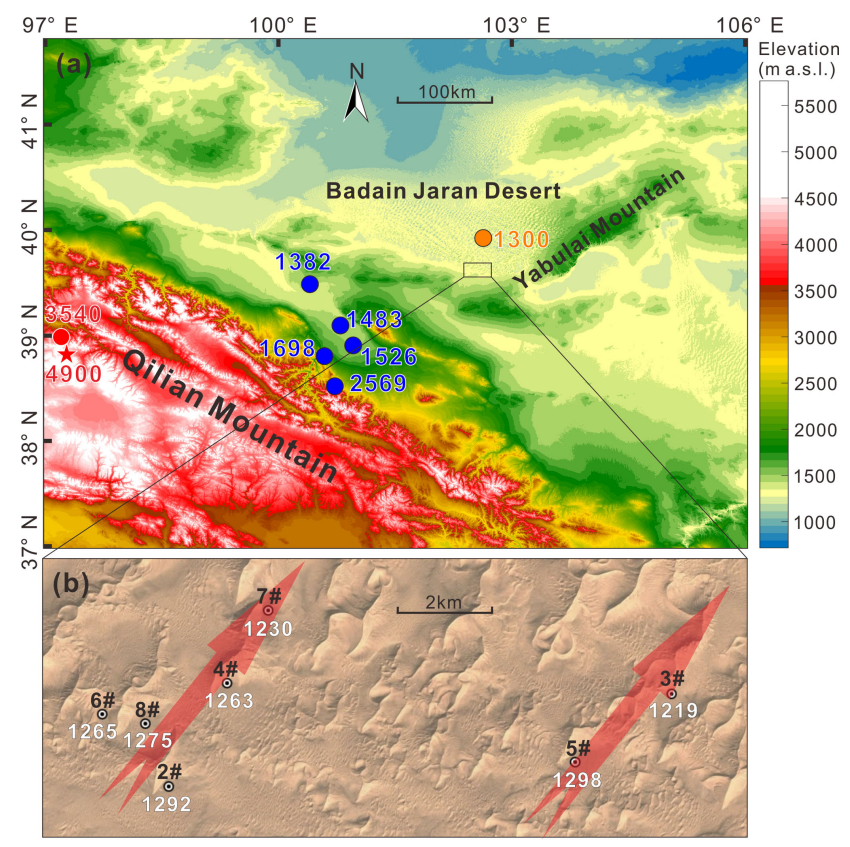

Figure 3. Elevation map of the Qilian Mountains and BJD areas (a) and groundwater wells drilled in the BJD (b). Locations for precipitation sampling in different areas are also shown in (a), as well as the elevation (m a.s.l.). The elevations of static groundwater levels in seven of the extraction wells (well no. 1 is far away from these wells and hence not shown) are indicated by white text in (b). Arrows in (b) show the estimated groundwater flow direction (based on groundwater elevation).

indicated that most of these river samples are likely to be mixtures of snowmelt water and piedmont precipitation. Isotope signatures show little connection between these rivers on the northern slope and the groundwater in the BJD.

The relationship between $d$-excess and $\delta^{18} \mathrm{O}$ was also discussed by $\mathrm{Wu}$ et al. (2017). The $d$-excess value ( $d$ excess $\left.=\delta \mathrm{D}-8 \delta^{18} \mathrm{O}<0\right)$ indicates the deviation from the GMWL, reflecting the degree of evaporation experienced by the available water. Wu et al. (2017) noted the difference in the $d$-excess value between the Qilian-sourced water (sampled from the northern slope rivers of the Qilian Mountains region) and BJD groundwater, and argued that the Qilian Mountains cannot be the origin of the latter because no evaporation could occur to water underground. Located in the northeastern margin of the Qinghai-Tibet Plateau, the Qilian Mountains area consists of many northwest-southeast parallel mountain ranges and valleys (Qiu et al., 2016). Although little evidence of evaporation was found in sampled river water from the northern slope area, water in other near-surface water systems (like lakes, wetlands, and soil water reservoirs) of longer residence time within the wide Qilian Mountains region would have been subjected to more intense evaporation and produced isotopic signatures similar to that of the
BJD groundwater. The $d$-excess results cannot exclude the Qilian Mountains as a recharge region either.

Groundwater in the BJD has also been postulated to be sourced from the Yabulai Mountain region (Fig. 3a). The highest mountain there is $1938 \mathrm{~m}$ a.s.l., which is unlikely to provide rainfall input with depleted heavy isotopes as shown in Fig. 2. In a recent groundwater resource development project, eight wells were drilled (depths of 135 to $260 \mathrm{~m}$ ) in the southeastern part of the BJD. The static groundwater levels in these wells show a decreasing trend from southwest to northeast (Fig. 3b), indicating an overall movement of groundwater along this direction. The groundwater flow direction is consistent with our hypothesis that BJD groundwater originates from the Qilian Mountains (located southwest of the BJD). Researchers have also examined the chemistry of lake water and groundwater in the study area and surrounding areas. For example, Yang and Williams (2003) investigated the ion chemistry of lake water and groundwater from the BJD and its periphery, and ruled out the possibility of recharge from recent local rainfall to the lakes and groundwater. In a previous study (Chen et al., 2012), the hydrochemical and isotopic results also supported our remote recharge hypothesis.

We agree with the concern of Wu et al. (2017) on the accuracy of ${ }^{14} \mathrm{C}$ dating for the $\mathrm{BJD}$ groundwater, which provided estimates of very old ages. Recent work (Wang and Chen, 2018) found considerable overestimation of the groundwater age by the ${ }^{14} \mathrm{C}$ dating method due to neglect of dead carbon brought on by deep $\mathrm{CO}_{2}$ emission. In contrast to the fossil groundwater hypothesis, the detectable tritium activities as shown by Wu et al. (2017) and many others (Chen et al., 2006; Gates et al., 2008; Yang and Williams, 2003) indicate a modern precipitation source of the BJD groundwater. This suggests that the Qilian Mountains-sourced groundwater flows through hundreds of kilometers over only tens of years. We suggest that, due to geological activities, various southwest-northeast deep fault systems exist between the Qilian Mountains and the desert (Chen et al., 2006). Based on the geological conditions and geochemical evidence (helium results), these large deep fault systems are hypothesized to act as a quick passage for the groundwater (Chen et al., 2006, 2004, 2012), which explains the detectable tritium in the groundwater.

The reanalysis above supports the hypothesis that groundwater in the BJD mainly originates from modern precipitation of the Qilian Mountains. Near-surface water in the Qilian Mountains, subjected to evaporation, infiltrates and recharges groundwater, which is then delivered to the BJD through the deep interconnected faults. Of course, more work is needed to support this hypothesis conclusively. It should also be noted that the higher average elevation (4000 to $5000 \mathrm{~m}$ a.s.l.) of the Qilian Mountains than the estimated mean recharge elevation (3914 ma.s.l.) estimated in this study, as well as the large variation of isotope composition of groundwater in the BJD, may imply a mixture of the Qilian- 
sourced water (of more depleted isotope composition from 4000 to $5000 \mathrm{~m}$ a.s.1.) with precipitation from other lower areas. Groundwater might have mixed with rainwater from low-elevation areas on its pathway.

\section{Concluding remarks}

We reanalyzed the precipitation isotope data of the Zhangye station to determine the original source of the groundwater in the Badain Jaran Desert. These data were averaged arithmetically in the recent study of Wu et al. (2017), whereas weighted averaging is more appropriate. The reanalysis does not support the conclusion of Wu et al. (2017) that the BJD groundwater is sourced from local meteoric water. Indeed, the reanalysis suggests a mean recharge elevation of about $3914 \mathrm{~m}$ a.s.l. for the BJD groundwater, which indicates that the precipitation in the Qilian Mountains region is a more likely main source of the BJD groundwater, as initially hypothesized by Chen et al. (2004).

Data availability. The data in this study are available from the publications that are listed in the reference section.

Author contributions. JC and LL put forward the idea of this comment. LZ did the data collection and analysis. LZ prepared the paper following continuous discussions with JC, LL and DAB. LL and $\mathrm{DAB}$ further improved the logicality and language of the paper.

Competing interests. The authors declare that they have no conflict of interest.

Acknowledgements. This research was supported by China Postdoctoral Science Foundation (No. 2018M630503). We thank the editor and two anonymous reviewers for providing valuable comments and suggestions.

Edited by: Christine Stumpp

Reviewed by: two anonymous referees

\section{References}

Bourque, C. P. A. and Hassan, Q. K.: Vegetation control in the long-term self-stabilization of the Liangzhou Oasis of the Upper Shiyang River watershed of westcentral Gansu, Northwest China, Earth Interact., 13, 1-22, https://doi.org/10.1175/2009EI286.1, 2009.

Chen, J. S., Li, L., Wang, J. Y., Barry, D. A., Sheng, X. F., Zu Gu, W., Zhao, X., and Chen, L.: Groundwater maintains dune landscape, Nature, 432, 459-460, https://doi.org/10.1038/nature03166, 2004.
Chen, J., Zhao, X., Sheng, X., Dong, H., Rao, W., and Su, Z.: Formation mechanisms of megadunes and lakes in the Badain Jaran Desert, Inner Mongolia, Chinese Sci. Bull., 51, 3026-3034, https://doi.org/10.1007/s11434-006-2196-8, 2006.

Chen, J. S., Sun, X. X., Gu, W. Z., Tan, H. B., Rao, W. B., Dong, H. Z., Liu, X. Y., and Su, Z. G.: Isotopic and hydrochemical data to restrict the origin of the groundwater in the Badain Jaran Desert, Northern China, Geochem. Int., 50, 455465, https://doi.org/10.1134/S0016702912030044, 2012.

Chen, X., Chen, J., and Wang, T.: A discussion of groundwater dating in Northern China, Water Resour. Prot., 30, 1-5, https://doi.org/10.3969/j.issn.1004-6933.2014.02.001, 2014 (in Chinese).

Dong, Z., Qian, G., Lv, P., and Hu, G.: Investigation of the sand sea with the tallest dunes on Earth: China's Badain Jaran Sand Sea, Earth-Science Rev., 120, 20-39, https://doi.org/10.1016/j.earscirev.2013.02.003, 2013.

Gates, J. B., Edmunds, W. M., Darling, W. G., Ma, J., Pang, Z., and Young, A. A.: Conceptual model of recharge to southeastern Badain Jaran Desert groundwater and lakes from environmental tracers, Appl. Geochem., 23, 3519-3534, https://doi.org/10.1016/j.apgeochem.2008.07.019, 2008.

Li, Z., Qi, F., Wang, Q. J., Song, Y., Aifang, C., and Jianguo, L.: Contribution from frozen soil meltwater to runoff in an in-land river basin under water scarcity by isotopic tracing in northwestern China, Glob. Planet. Change, 136, 41-51, https://doi.org/10.1016/j.gloplacha.2015.12.002, 2016.

Ma, J. and Edmunds, W. M.: Groundwater and lake evolution in the Badain Jaran Desert ecosystem, Inner Mongolia, Hydrogeol J., 14, 1231-1243, https://doi.org/10.1007/s10040-006-0045-0, 2006.

Poage, M. A. and Chamberlain, C. P.: Empirical relationships between elevation and the stable isotope composition of precipitation and surface waters: Considerations for studies of paleoelevation change, Am. J. Sci., 301, 1-15, https://doi.org/10.2475/ajs.301.1.1, 2001.

Qiu, X., Zhang, M., and Wang, S.: Preliminary research on hydrogen and oxygen stable isotope characteristics of different water bodies in the Qilian Mountains, northwestern Tibetan Plateau, Environ. Earth Sci., 75, 1491, https://doi.org/10.1007/s12665016-6299-5, 2016.

Ren, J.: A study of chemical characteristics of snow, precipitation and surface water in the basin of the glacier No. 29 in Danghe Nanshan, Qilian Mountains, J. Glaciol. Geocryol., 21, 151-154, 1999 (in Chinese).

Wang, F., Sun, D., Chen, F., Bloemendal, J., Guo, F., Li, Z., Zhang, Y., Li, B., and Wang, X.: Formation and evolution of the Badain Jaran Desert, North China, as revealed by a drill core from the desert centre and by geological survey, Palaeogeogr. Palaeoclimatol. Palaeoecol., 426, 139-158, https://doi.org/10.1016/j.palaeo.2015.03.011, 2015.

Wang, T. and Chen, J.: Overestimated groundwater ${ }^{14} \mathrm{C}$ ages triggered an inexpediency of water policy in China, Curr. Sci., 114, 1-4, https://doi.org/10.18520/cs/v114/i08/1751-1755, 2018.

Wu, J., Ding, Y., Ye, B., Yang, Q., Zhang, X., and Wang, J.: Spatiotemporal variation of stable isotopes in precipitation in the Heihe River Basin, Northwestern China, Environ. Earth Sci., 61, 1123 1134, https://doi.org/10.1007/s12665-009-0432-7, 2010. 
Wu, X., Wang, X.-S., Wang, Y., and Hu, B. X.: Origin of water in the Badain Jaran Desert, China: new insight from isotopes, Hydrol. Earth Syst. Sci., 21, 4419-4431, https://doi.org/10.5194/hess-214419-2017, 2017.

Yang, X. and Williams, M. A. J.: The ion chemistry of lakes and late Holocene desiccation in the Badain Jaran Desert, Inner Mongolia, China, Catena, 51, 45-60, https://doi.org/10.1016/S03418162(02)00088-7, 2003

Yang, X., Ma, N., Dong, J., Zhu, B., Xu, B., Ma, Z., and Liu, J.: Recharge to the inter-dune lakes and Holocene climatic changes in the Badain Jaran Desert, western China, Quat. Res., 73, 10-19, https://doi.org/10.1016/j.yqres.2009.10.009, 2010.
Zhan, L., Chen, J., Xu, Y., Xie, F., and Wang, Y.: Allogenic water recharge of groundwater in the Erenhot wasteland of northern China, J. Radioanal. Nucl. Chem., 311, 2015-2028, https://doi.org/10.1007/s10967-017-5175-4, 2017.

Zhao, L., Xiao, H., Dong, Z., Xiao, S., Zhou, M., Cheng, G., Yin, L., and Yin, Z.: Origins of groundwater inferred from isotopic patterns of the Badain Jaran Desert, Northwestern China, Ground Water, 50, 715-725, https://doi.org/10.1111/j.17456584.2011.00895.x, 2012.

Zhu, G. F., Su, Y. H., and Feng, Q.: The hydrochemical characteristics and evolution of groundwater and surface water in the Heihe River Basin, northwest China, Hydrogeol. J., 16, 167-182, https://doi.org/10.1007/s10040-007-0216-7, 2008. 